PWE-127

\title{
THE EFFECTS OF ANTIMUSCARINIC AGENTS ON RECTAL COMPLIANCE IN PATIENTS WITH SUPRACONAL SPINAL CORD INJURY
}

doi:10.1136/gut.2011.239301.390

A J Paily, $1^{1 *}$ G Preziosi, ${ }^{1}$ A Raeburn, ${ }^{1}$ A Emmanuel ${ }^{1} \quad{ }^{1}$ Gl Physiology, University College Hospital London, London, UK

Introduction Constipation affects up to $80 \%$ of spinal cord injury (SCI) patients and is cause of significant reduction of quality of life. Rectal compliance is determined by the rectal wall properties and by the supra-spinal modulation of the thoracic sympathetic and para-sympathetic lumbosacral efferents; it is increased in SCI patients with injury level above T5. Often this patient group has associated bladder dysfunction, and requires antimuscarinic agents (Tolterodine or Solifenacin), which are known to cause constipation. The authors aimed to assess the physiological effect of antimuscarinic agents on the anorectal function of patients with SCI above T5.

Methods The authors prospectively collected data from 17 SCI patients (11 males, mean age 41 , mean disease duration 13 months) attending a neuro-gastroenterology clinic at a tertiary centre. All had an established SCI above T5, and 11 had a complete injury. Anal manometry, assessment of rectoanal inhibitory reflex (RAIR) and rectal compliance were measured at baseline, and after antimuscarinic treatment was started (mean follow-up 12 weeks).

Results Anal sphincter function parameters of squeeze and cough pressure were unchanged after antimuscarinic treatment (pre vs post $123 \pm 40$ vs $122 \pm 36 p=0.827 ; 88 \pm 24$ vs $87 \pm 26$ $\mathrm{p}=0.859$ respectively). However, resting anal pressure and rectal compliance were significantly raised after antimuscarinic treatment $(82 \pm 18$ vs $88 \pm 16 p=0.058 ; 19.2 \pm 5.0$ vs $24.2 \pm 4.1$ $\mathrm{p}<0.001)$. When analysing the three components of the RAIR, the percent amplitude of maximal sphincter relaxation was decreased (pre vs post $48 \% \pm 8 \%$ vs $37 \% \pm 6 \%$, p $=0.026$ ) 
and excitation latency was increased $(1.2 \pm 0.6$ vs $1.5 \pm 0.7 \mathrm{~s}$, $\mathrm{p}<0.001)$.

Conclusion In SCI patients the use of antimuscarinic agents causes increased rectal compliance, reduced reflex relaxation of the anal sphincter and delayed latency of this reflex. These physiological changes all predispose towards constipation. In the absence of cortical modulation, in patients with a SCI level above T-5, sympathetic activity is effectively enhanced. The effect of these drugs underlines the importance of tonic parasympathetic input to rectal compliance and anorectal reflex function.

Competing interests None.

Keywords antimuscarinic, compliance, supraconal. 